SHEPARD, R. N. Recognition memory for words, sentences, and pictures. Journal of Verbal Learning \& Verbal Behavior, 1967, 6, 156-163.

TVERSKY, A., \& KRANTZ, D. H. Similarity of schematic faces: A test of interdimensional additivity. Perception \& Psychophysics, 1969 $5,124-127$.
YIN, R. K. Looking at upside-down faces. Journal of Experimental Psychology, 1969, $81,141-145$

NOTE

1. Latency scores are not reported since they failed to offer any additional information. In addition, sex was not treated as a variable.

\title{
Part-whole transfer of a categorizable word list*
}

\author{
ROBERT L. HUDSON and JERRY L. DAVIS \\ Mississippi State University, State College, Miss. 39762
}

The Ss learned a part list where the words could be placed into one of four Underwood $\&$ Richardson (1956) categories and were then transferred to the whole list containing all the words of the part list plus additional words from each category. One group was told prior to part list learning that the words could be categorized, and another group was never given this information. An additional control group was included to assess the effects of information, per se. The results of whole-list learning, which were in the predicted direction but generally nonsignificant, showed a slight superiority for the group receiving information over the group not receiving information.

Tulving (1966) demonstrated that prior training on a part of a list of unrelated words resulted in negative transfer in learning of the whole list. The explanation offered by Tulving (1966) was that in the course of learning the part list, $\mathrm{S}$ forms subjective units which are inappropriate for organizing the whole list but which the $S$, nevertheless, carries over in his attempt to learn the whole list. Thus the persistence of old subjective units retards the discovery of new subjective units which would be optimal for organizing the whole list.

Bower \& Lesgold (1969) reasoned that if the $S$ could be forced into a part-list organization which would be compatible with the whole-list organization then positive transfer of number of words recalled should result. Their data indicated this to be true.

Hudson $(1968,1969)$ studied the effect on organization in recall (clustering) of giving Ss the category names of a list of words taken from the Underwood \& Richardson (1956) norms prior to random presentation of words from four categories. The data indicated that those Ss who had been given the category names evidenced significantly more E-defined organization than did Ss who had not been given this information. There was, however, no concomitant increase in the actual number

*This research was partially supported by institutional funds granted to Mississippi State University by the National Science Foundation.

† Requests for reprints should be sent to Robert L. Hudson, P.O. Drawer PF, State College, Miss. 39762. of words recalled, even though the correlations between the clustering index and the number of words recalled were relatively high within the separate groups. Thus, there seemed to be a paradox in that there is a tendency for Ss who cluster more to recall more words, yet, "artificially" increasing the tendency to organize into E-defined units did not increase the actual number of words recalled. The research literature, in general, has indicated that independent variables which affect clustering do not necessarily have an effect on the number of words recalled (see Cofer, 1967).

The present study was an attempt to demonstrate positive transfer of both clustering and number of words recalled in a part-to-whole transfer paradigm using words from the Underwood \& Richardson (1956) norms. If Ss learn a part list where they have been instructed that the words can be placed into categories, then prior research (Hudson, 1968, 1969) has indicated that the words will be organized around the category name while such E-defined organization in a no-information control is minimal. Therefore, when the whole list consists of the part list plus additional words from each category, one should expect that the part list organization would be effective for organizing the whole list. Therefore, this group should exceed a no-information control in both organization (clustering) and number of words recalled for at least the early trials of whole-list learning.

\section{SUBJECTS}

The Ss were 45 male and female introductory psychology students who served in order to fulfill a course requirement.

\section{MATERIALS}

Thirty-two words were chosen from the Underwood \& Richardson (1956) norms, with eight words from each of four categories. The category names and words used were as follows: Smalll: atom, germ, village, minnow, capsule, pup, pill, snail. Round: spool, dome, knob, head, button, saucer, balloon, platter. White: milk, bandage, snow, ivory, napkin, linen, rice, bread. Smelly: ammonia, skunk, ether, sewer, garlic, gasoline, pine, cigar.

Two part lists were developed, using half the words from each category. For a given category, the eight words were ranked in terms of response dominance. The odd-numbered ranks comprised one subset while the even-numbered ranks comprised a second subset. One part list was developed by choosing one subset at random from each category and the second part list was composed of the remaining four subsets. The mean response dominance for the words of the two part lists were 60.9 and 60.6 with standard deviations of 15.5 and 15.2 , respectively.

For both the two part lists and the whole list, the order of the words on the memory drum tape was determined at random. There were four random orders of each part list and eight random orders of the whole list. Two Stowe memory drums were used to present the words. Booklets were prepared, with four pages having 16 lines and eight pages having 32 lines.

\section{PROCEDURF}

Three sets of instructions define the three levels of the independent variable. The information-before (IB) group was told prior to starting the part task that the words could be put into categories, and they were told the category names. They were given this same information again prior to learning the whole list. The no-information (NI) group was never given any indication that the words could be categorized. The third group was an information-between (IBe) group. These $S$ s were told nothing about the categorical nature of the words prior to learning the part list but were given the information and the category names prior to learning the whole list. This group was included to determine if any differences which might result between the IB and NI groups were the result of transfer from the part list or simply the effects of the information. Thus, it was expected that the IBe group would not perform as well on at least the early trials of whole-list learning as would the IB group. The whole-list instructions made no statement conceming the fact that the list the Ss were about to learn was, in fact, composed partly of the previously 
Table 1

Mean Total Number of Words Recalled (TOT). Mean Number of Old Words Recalled (OLD). Vean Number of New Words Recalled (NEW), and Mean Clustering Indices (CI) for the Three Groups on Trials 1,3,5. and 7 of the Whole List

\begin{tabular}{|c|c|c|c|c|c|}
\hline \multirow[b]{2}{*}{ Measure } & \multirow[b]{2}{*}{ Condition } & \multicolumn{4}{|c|}{ Trial } \\
\hline & & 1 & 3 & 5 & $?$ \\
\hline TOT & $\begin{array}{l}\text { Information Before } \\
\text { Information Between } \\
\text { No Information }\end{array}$ & $\begin{array}{l}17.5 \\
16.1 \\
15.7\end{array}$ & $\begin{array}{l}23.9 \\
23.7 \\
20.8\end{array}$ & $\begin{array}{l}26.1 \\
26.1 \\
24.2\end{array}$ & $\begin{array}{l}27.2 \\
27.3 \\
24.7\end{array}$ \\
\hline OLD & $\begin{array}{l}\text { Information Before } \\
\text { Information Between } \\
\text { No Information }\end{array}$ & $\begin{array}{r}10.8 \\
8.1 \\
10.6\end{array}$ & $\begin{array}{l}12.5 \\
11.6 \\
10.8\end{array}$ & $\begin{array}{l}13.3 \\
13.1 \\
11.9\end{array}$ & $\begin{array}{l}13.2 \\
13.3 \\
11.8\end{array}$ \\
\hline NEW & $\begin{array}{l}\text { Information Before } \\
\text { Information Between } \\
\text { No Information }\end{array}$ & $\begin{array}{l}6.7 \\
8.0 \\
5.1\end{array}$ & $\begin{array}{l}11.3 \\
12.1 \\
10.0\end{array}$ & $\begin{array}{l}12.9 \\
13.1 \\
12.3\end{array}$ & $\begin{array}{l}13.9 \\
14.1 \\
12.9\end{array}$ \\
\hline $\mathrm{CI}$ & $\begin{array}{l}\text { Information Before } \\
\text { Information Between } \\
\text { No Information }\end{array}$ & $\begin{array}{r}1.6 \\
1.5 \\
-0.1\end{array}$ & $\begin{array}{l}3.2 \\
3.5 \\
1.3\end{array}$ & $\begin{array}{l}3.5 \\
4.0 \\
0.6\end{array}$ & $\begin{array}{l}4.2 \\
4.6 \\
0.3\end{array}$ \\
\hline
\end{tabular}

learned list.

The Ss were assigned randomly to the three conditions in blocks of three and were run individually. There were $15 \mathrm{Ss}$ in each of the three groups. Eight of these received one part list and seven received the other. Each $S$ was assigned randomly to one of four starting positions on his part list and to one of eight starting positions on the whole list. Each $S$ received four presentation-recall trials on the part list with the words being presented at a $3.5-\mathrm{sec}$ rate. One minute was allowed for recall on each trial. The $\mathrm{S}$ was then read appropriate instructions for the whole list and given eight presentation-recall trials on the whole list at a 2.5 -sec rate. Two and one-half minutes were allowed for each recall of the whole list.

\section{RESULTS}

The mean total number of words recalled over the four trials of the part list were $43.8,43.2$, and 41.0 for the IB, IBe, and NI groups, respectively. A completely randomized analysis of variance indicated an insignificant $F$ ratio $(F<1)$ for total number of words recalled over the four trials. The mean clustering indices for the fourth trial of the part list were $1.29, .32$, and .22 for the IB, IBe, and NI groups, respectively. A completely randomized analysis of variance indicated a significant difference in clustering, $F(2,42)=5.74$, $p<.01$. Subsequent analysis by use of Tukey's HSD test indicated that the IB group significantly exceeded $(p<.05)$ the $\mathrm{IBe}$ and NI groups between which there was no difference. The clustering index used was one presented by Dunn (1969).

Table 1 indicates the mean total number of words recalled, mean number of "old" words recalled, mean number of "new" words recalled, and mean clustering indices for the three groups for Trials 1.3, 5, and 7 of the whole list learning.

A 3 by 8 split-plot analysis of variance for the total number of words recalled (old plus new) over all eight trials revealed the following: conditions $F(2,42)=1.81$. $p>.05$; trials $F(7,294)=92.75, p<.01$ : interaction $F(14,294)<1$.

A 3 by 8 split-plot analysis of variance over all eight trials for the number of new words recalled revealed the following: conditions $F(2,42)=2.42, p>.05$; trials $F(7,294)=89.59, \quad p<.01 ; \quad$ interaction $F(14,294)=.91, p>.05$.

A 3 by 8 split-plot analysis of variance for the number of old words over all eight trials revealed the following: conditions $\mathrm{F}(2,42)=1.22, \mathrm{p}>.05 ;$ trials $F(7,294)=19.25, \quad p<.01 ; \quad$ interaction $F(14,294)=3.22, \quad p<.01$. Subsequent comparisons of the simple main effects of the three groups at each trial indicated significance only on Trial 1, where both the IB and NI groups significantly exceeded the $\mathrm{IBe}$ group. This finding supports previous research on the effects of disrupted organization (see Earhard, 1969; Hudson, 1969).

A 3 by 8 split-plot analysis of variance of the four-category clustering index over all eight trials revealed all $F$ ratios significant: conditions $F(2,45)=19.83$, $\mathrm{p}<.01 ;$ trials $\mathrm{F}(7,294)=17.25, \mathrm{p}<.01$; interaction $F(14,294)=3.42, \quad p<.01$. Subsequent analyses of simple main effects for trials at each condition indicated a significant $(p<.01)$ increase over trials for both the IB and IBe groups and an insignificant increase over trials for the NI group. Subsequent comparisons between the three groups at each trial indicated that the IB and IBe groups significantly (ps $<.05)$ exceeded the NI group at each trial but were never significantly different from each other. The clustering index used was one presented by Dunn (1969).

\section{DISCUSSION}

The trend of the results was in the predicted direction, although the differences were not large enough to be reliable. The IB group exceeded the NI group by an average of 2.58 words per trial. The IB group exceeded the IBe group an average of 1.4 words on the first trial. with no appreciable difference on the following trials.

Even though the results of this study do not provide strong evidence indicating a positive relationship between the amount of clustering and the number of words recalled, they are of enough interest to warrant documentation. Furthermore, even in the absence of significant results, the methodology employed in this study would seem to have merit for continued investigation of the relationship between clustering and the number of words recalled. The most obvious problem was the lack of more clustering in the early trials on the part of the IB group as compared with the IBe group. In th absence of positive transfer of organization one would hardly expect a positive transfer of number of words recalled. The IB group was clustering significantly more than either of the other groups on the last trial of part learning. but the mean clustering index was still far short of the maximum amount. Subsequent investigations should manipulate relevant variables so as to increase the amount of clustering in the late trials of part-list learning.

It might also be advantageous to employ taxonomic categories as the organizational structure of such a list would be more readily evident. This would, of course, necessitate the use of two or more different part lists, which is a procedure also having inherent difficulties.

\section{REFERENCES}

BOWER, G., \& LESGOLD, A. M. Organization as a determinant of part-to-whole transfer in free recall. Journal of Verbal Learning \& Verbal Behavior. 1969, 8, 501-506.

COFER, C. "Does conceptual organization influence the amount retained in immediate free recall?" In B. Kleinmuntz (Ed.). Concepts and the structure of memory. New York: Wiley, 1967. Pp. 181-214.

DLNN, J. E. A compound multiple runs distribution. Journal of the American Statistical Association, 1969, 64, 1415-1423. EARHARD, M. Storage and retrieval of words encoded in memory. Journal of Experimental Psychology, 1969, 80, 412-418.

HLDSON, R. L. Category clustering as a function of level of information and number of stimulus presentations. Journal of Verbal Learning \& Verbal Behavior, 1968, 7, 1106-1108.

HUDSON, R. L. Category clustering for immediate and delayed recall as a function of recall cue information and response dominance variability. Journal of Experimental Psychology, 1969, 82, 575-577.

TULVING, E. Subjective organization and effects of repetition in multi-trial free-recall learning. Journal of Verbal Learning \& Verbal Behavior, 1966. 5, 193-197.

LNDERWOOD, B. J., \& RICHARDSON, J. Some verbal materials for the study of concept formation. Psychological Bulletin, 1956, 53, 84-95. 